\title{
Challenges in Neonatal Screening in Health Care System
}

\section{AR. Mullaicharam}

Oman Medical College, Pharmacy Department, Muscat, Oman

\section{Introduction}

Neonatal screening is a vital process that identifies apparently healthy neonates with serious inherited disorders, which are generally metabolic in origin and correctable by dietary or drug interventions. Inborn errors of metabolism are rare in isolation, but collectively are common. They usually present in the neonatal period or infancy, but can occur at any time, even in adulthood [1].

The concept of screening newborns no longer refers only to the screening tests themselves but includes all of the elements essential for every neonate to have access to a screening system that is optimal in terms of quality and performance [2]. Comprehensive screening programs for congenital diseases of newborn infants are lacking at a international level.

Screening programs for congenital diseases of newborn infants have been in effect for several decades in some countries. More than 30 diseases can be screened for in the neonatal period, and this list is growing [3-8].

\section{There are ten challenges to successfully implement a sustainable program of new born screening:}

Planning: The momentum is created through visionary ideas that can be molded into a systematic approach to a sustainable national NDBS program. Once logically developed, the program plan provides a foundation on which to establish the other elements necessary for success.

Leadership: Successful program implementation usually requires passionate leadership (individual or group) with an ability to understand and address. Leaders must clearly convey ideas and successfully motivate others. The initiation of a new program or new ideas usually requires time, and leaders must be willing to make the required time investment.

Education: New ideas result from the accumulation and transfer of new knowledge. The education of professionals, policymakers and the public must be provided in a carefully thought-out way that addresses stakeholder concerns that may adversely affect successful program implementation.

Medical support: For a new or expanded medical program, such as program of new born screening:, to succeed, the medical community must accept it. Program leaders must have sufficient knowledge and vision to address medical questions in a manner that builds confidence and collaboration among peers. Successful NDBS requires timely and appropriate diagnosis and treatment, which requires the cooperation of primary care and specialty healthcare providers.

Technical support: Because NDBS analytical protocols are microtechniques that differ from routine medical laboratory tests; implementation usually requires some technical training and knowledge sharing. Similarly, specimen collection and transport as well as the post-analytical processes of result reporting and followup (including clinical and laboratory confirmation) are essential pre-analytical processes that must be properly executed. Analytical

\section{Publication History:}

Received: May 31, 2018

Accepted: July 03, 2018

Published: July 05, 2018

\section{Keywords:}

Neonatal screening, Health care system, Newborn infants, Policy development

technical support is often available from product vendors specializing in NDBS, and pre- and post-analytical support can be obtained from other more developed NDBS programs.

Logistical support: Mechanisms must be developed for obtaining and distributing blood collection supplies, training the testing and followup personnel, transporting specimens to the screening laboratory(ies), providing for screening laboratory operations (equipment, supplies and maintenance), maintaining appropriate records, and reporting the screening results quickly while addressing cultural and other sensitivities.

Protocol/policy development: Institutionalized policies and protocols addressing all NDBS system components prevent confusion and unnecessary overlap. Six system components should be addressed: education, screening (including considerations of consent/dissent for testing, data sharing, and residual specimen storage and use), followup/tracking, diagnosis, treatment/management, and evaluation/ quality improvement. A comprehensive listing of possible program elements that may be included in policy/ protocol development [Program Evaluation and Assessment Scheme (PEAS)] has been published and may provide a useful planning tool.

Administration: Strong leadership, planning and policy development should lead to efficient and effective program administration/ management. Successful patient outcomes will be achieved with properly functioning program components and timely and optimized medical management. Good program administration should ensure that improved newborn health is attainable within the confines of the healthcare system.

Evaluation: Outcome monitoring by observation of disorder-specific sentinel events provides a means for program of new born screening evaluation and should be designed to assist with continuing program improvements. Similarly, indicators of the successful function of other program of new born screening, system components, including external laboratory proficiency testing, should be monitored as partof an overall quality assurance program. The PEAS tool noted earlier has been modified for this purpose in at least one NDBS program .

"Corresponding Author: Dr. AR. Mullaicharam, Oman Medical College, Pharmacy Department, Muscat, Oman; E-mail: mullai@edu.om

Citation: Mullaicharam AR (2018) Challenges in Neonatal Screening in Health Care System. Int J Clin Pharmacol Pharmacother 3: 139. doi: https://doi. org/10.15344/2456-3501/2018/139

Copyright: (C) 2018 Mullaicharam. This is an open-access article distributed under the terms of the Creative Commons Attribution License, which permits unrestricted use, distribution, and reproduction in any medium, provided the original author and source are credited. 
Sustainability: To become sustainable, the program of new born screening must be integrated into a functioning public health system and be adequately financed. Some countries have been successful in obtaining approval for financing through national public health insurance programs, but this process is often slow and incomplete. As a result, other financing schemes, including a fee system, should be considered. Many developed programs implore a system in which birthing facilities purchase screening kits (collection cards) and are responsible for their own eimbursement. In such cases, care must be taken to limit the administrative/collection charges that may be added to the test cost to the patient; otherwise, the patient charges will become excessive and counterproductive. When fees are considered, all program costs, including both laboratory and non-laboratory screening elements (i.e., program administration, equipment, education, public relations, follow-up, and specimen storage), must be considered [9].

Traditionally the inherited metabolic diseases were classified as disorders of

1. Carbohydrate metabolism,

2. Amino acid metabolism,

3. Organic acid metabolism or lysosomal storage diseases.

In recent decades, hundreds of new inherited disorders of metabolism have been discovered and the categories have proliferated. Following are some of the major classes of congenital metabolic diseases, with prominent examples of each class. Many others do not fall into these categories.

\begin{tabular}{|c|c|}
\hline $\begin{array}{l}\text { Inborn Error } \\
\text { Metabolism }\end{array}$ & Examples[10]. \\
\hline $\begin{array}{l}\text { Urea cycle } \\
\text { disorders }\end{array}$ & $\begin{array}{l}\text { Ornithine transcarbamylase deficiency, } \\
\text { citrullinemia, argininosuccinic aciduria, } \\
\text { argininemia }\end{array}$ \\
\hline $\begin{array}{l}\text { Organic } \\
\text { acidemias }\end{array}$ & $\begin{array}{l}\text { Propionic acidemia, methylmalonic aciduria, } \\
\text { isovaleric acidemia, glutaric acidemia, maple } \\
\text { syrup urine disease }\end{array}$ \\
\hline $\begin{array}{l}\text { Fatty acid } \\
\text { oxidation defects }\end{array}$ & $\begin{array}{l}\text { Medium chain acyl-CoA dehydrogenase } \\
\text { deficiency, carnitine palmitoyl transferase } \\
1 \text { deficiency, long chain hydroxyacyl-CoA } \\
\text { dehydrogenase deficiency }\end{array}$ \\
\hline $\begin{array}{l}\text { Amino } \\
\text { acidopathies }\end{array}$ & Tyrosinemia, phenylketonuria, homocysteinuria \\
\hline $\begin{array}{l}\text { Carbohydrate } \\
\text { disorders }\end{array}$ & Galactosemia, fructosemia \\
\hline $\begin{array}{l}\text { Mitochondrial } \\
\text { disorders }\end{array}$ & $\begin{array}{l}\text { MELAS, MERFF, pyruvate dehydrogenase } \\
\text { deficiency }\end{array}$ \\
\hline
\end{tabular}

In the outlook, expanding communication technologies will likely play a larger role in educating parents and professionals regarding program of new born screening. In developing healthcare systems, communication technologies should be particularly useful for data and result transfer and for improved vendor support of testing equipment and other supplies critical to the screening process. Strategic planning as well as multi-national collaborations will continue to be critical to sustainable program of new born screening. Necessary information for policy decisions originate from data and it is important that national and regional data be standardized, collected centrally and periodically analyzed. Programs should be aware of developing international information technology standards and definitions such that they may be considered during planning deliberations. New technologies continue to be developed to result in an increased number of screening possibilities, and efforts must be made in developing programs to stay abreast of technological changes that may affect screening protocols and policies[9].

\section{Conflict of Interest}

The authors declare no conflict of interest.

\section{References}

1. Shaafie IA, Raju ADV, Menon PK (2016) Neonatal screening for inborn errors of metabolism-our experience at CABRI, Gulf Medical University. Gulf Medical Journal 5: S35-S42.

2. American Academy of Pediatrics (1992) Committee on Genetics: issues in newborn screening. Pediatrics 89: 345-349.

3. American Academy of Pediatrics, American Thyroid Association (1987) Newborn screening for congenital hypothyroidism: recommended guidelines. Pediatrics 80: 745-749.

4. Task Force on genetic screening (1976) The pediatrician and genetic screening (every pediatrician a geneticist). Pediatrics 58: 757

5. World Health Organization working group (1982) Hereditary anemias, genetic bases, clinical features, diagnosis and treatment. Bull WHO 60: 643660.

6. Hsia YE, Wolf B (1981) Inherited Metabolic Disorder. In: Avery G, ed Neonatology Pathophysiology and Management of the Newborn, ed 2. Philadelphia: JB Lippincott.

7. Grover R, Wethers D, Shahidi S, Grossi M, Goldberg D, et al. (1978) Evaluation of the expanded newborn screening program in New York city. Pediatrics 761: 740-749.

8. Schneider RG, Hightower B, Hosty TS, Ryder H, Tomlin G, et al. (1976) Abnormal hemoglobins in a quarter million people. Blood 48: 629-637.

9. Therrell BL, Padilla CD (2014) Padilla Barriers to implementing sustainable national newborn screening in developing health systems. International Journal of Pediatrics and Adolescent Medicine 1: 49-60.

10. https://www.genome.gov/27551373/the-nih-mini-study-generalinformation-about-inborn-errors-of-metabolism/ 